\title{
Göknar (Abies bornmülleriana Mattf.) Ahşabının Yüzey Pürüzlülüğü Üzerine Zımparalama ve Kesiş Yönünün Etkisi
}

\section{The Impact of Sanding and Section Direction on Surface Roughness of Fir Wood (Abies bornmülleriana Mattf.)}

\author{
Ferhat ÖZDEMIR ${ }^{1 *}$, Eda DALGIÇ ${ }^{1}$,Hamit ÖZYURT', Doğu RAMAZANOĞLU ${ }^{2}$, Ahmet TUTUŞ
}

${ }^{1}$ Kahramanmaraş Sütçü İmam Üniversitesi, Orman Endüstri Mühendisliği Bölümü, Kahramanmaraş, Türkiye

${ }^{2}$ Kahramanmaraş Sütçü İmam Üniversitesi, Malzeme Bilimi ve Mühendisliği Bölümü, Kahramanmaraş, Türkiye

\section{ÖZET}

Bu çalışmada Göknar (Abies bornmülleriana Mattf) ahşabının yüzey pürüzlülüğ̈̈ üzerine zımparalama ve kesiş yönünün etkisi araştırılmıştır. Daire testere ile radyal ve teğet yönde kesilen göknar ahșap numuneleri sirasiyla 60, 80, 100 ve 150 numaralı zımpara ile zımparalama işlemi uygulanmıştır. Zımparalama işlemi yapılan numunelerin yüzey pürüzlülük parametre değerleri ISO 4287 standardına göre ölçülmüştür. Elde edilen verilere göre yüzey pürüzlülük değeri hem radyal hem de teğet yönde zımpara numarasının artmasına bağl olarak iyileşme göstermiştir. Radyal yöndeki yüzey pürüzlülük parametrelerine klyasla teğet yönde iyileşmenin daha fazla olduğu belirlenmiştir.

Anahtar Kelimeler: Zımparalama, Göknar, Yüzey Pürüzlülüğü, Radyal ve Teğet Kesit

\section{ABSTRACT}

In this study the effect of sanding and section direction on the surface roughness of Fir (Abies bornmülleriana Mattf.) wood was investigated. Using circular saws, the radial and tangential fir wood samples were subjected to sanding with sandpaper numbers $60,80,100$ and 150 respectively. Surface roughness parameter values of the samples subjected to sanding were measured according to ISO 4287 standard. According to the obtained data, the surface roughness value has improved due to the increase of the sanding number in both radial and tangential directions. It is determined that this improvement is more in the tangential direction than the surface roughness parameters in the radial direction.

Keywords: Sanding, Fir Wood, Surface Roughness, Radial and Tangential Section

\section{GíRiş}

Göknar Kuzey ve Orta Amerika, Asya, Avrupa, Kuzey Afrika'da ve Kuzey Yarımkürenin mutedil ve serin bölgelerinde dağılış göstermiştir. Herdem yeşil, dalları gövdeye çevrel dizilmiş genç yaşlarda piramidal ve orta yaşlarda konik bir tepeye sahip boylu orman ağaçlarıdır. Açık gri renkli kabuklara sahiptir, yaşlılarda ise kabuk çatlaklı ve kalındır. Çoğunlukla reçineli tomurcukları vardır. Göknar ahşapları türlere göre değişmekle beraber çoğunlukla kırmızımtırak-kahverengi, beyaz veya beyaz-sarımtırak ve kokusuzdur. Göknar ahşapları kolay işlenmesi ve yumuşak olması nedeniyle düzgün ve pürüzsüz bir yüzey vermekte olup bu nedenle iyi boya ve cila kabul etmektedir (Yaltırık ve Efe, 2000).

Ahşap ve ahşap esaslı ürünlerin üretiminde yüzey yapısı, malzemelerin işlenmesi sırasında birçok aşamayı etkilemektedir. $\mathrm{Bu}$ aşamalar ürün kalitesini, ürün sınıfını, tutkallamayı, verniklemeyi ve ahşap yüzeyinde işlem uygulama kolaylığını etkilemektedir. Yüzey pürüzlülüğü ürün çeşidine göre değişmektedir (Funck ve ark, 1993). Yüzey pürüzlülüğü işlenen malzemenin yüzeyinde oluşan dalgalanma hatalarının dışında kalan küçük ve periyodik bir şekilde tekrarlanan düzensizliklere denilmektedir (Peters ve Cumming, 1970; Stumbo, 1963).

Ahşap esaslı levhaların yüzeyleri, yüzey kaplama malzemeleri ile kaplanmaktadır. Yüzeyler öncelikle zımparalanma işleminden geçirilmektedir. Kaplama malzemelerinde yüzey pürüzlülük değeri yüzey tutunma direncini etkiler. Yüzey pürüzlülük değerleri üretim öncesi ve sonrası yapılan yüzey işlemlerine bağlıdır. Yüzey pürüzlülüğü mekanik özellikleri de etkileyen bir faktördür (Kılıç ve ark, 2009).

Yapışmayı etkileyen en önemli faktörlerden biri yüzey pürüzlülügüüür. Yüzey düzgünlüğü arttıkça yüzey ve yapıştırıcı arasındaki temas alanı da artmaktadır. Yüzey alanı arttığından yapışma özelliği ve iki yüzey arasında çekim alanı da artmaktadır. Bu sebeplerden yüzey işleminin başarısı yüzey düzgünlüğüne ve zımparalama işlemine bağlıdır (Ayrılmış ve ark., 
2010; Hızıroğlu, 1996). Yalçın Örs ve ark., ve Brad J. Schoenfeldve ark. zımpara numarasının artmasıyla yüzey pürüzlülüğünün azaldığını yapılan çalışmalarda bildirmişlerdir (Örs ve Baykan, 1999; Örs ve Demirci, 2003; Schoenfeld ve ark., 2014).

Farklı ağaç türlerinde yüzey düzgünlüğü ile ilgili bazı çalışmalar yapılmıştır ancak zımparalama işleminin Göknar ahşabını kesiş yönü üzerine etkisi ile ilgili çalışma bulunmamaktadır. Bu çalışmada, Göknar (Abies bornmülleriana Mattf.) ahşabı teğet ve radyal yönlerde kesilerek farklı zımpara numaraları ile zımparalama işlemine tabi tutulmuştur. Daha sonra yüzey pürüzlülük değerleri incelenen numuneler üzerinde zımparalamanın ve kesiş yönünün yüzey pürüzlülüğü üzerine etkisi araştırılmıştır.

\section{MATERYAL VE METOT}

Göknar (Abies bornmülleriana Mattf.) ahşabı daire testere ile radyal (R) ve teğet (T) yönde olmak üzere kesilerek test numuneleri elde edilmiştir. Numuneler zımpara yapılmadan önce $20^{\circ} \mathrm{C} \pm 2$ sıcaklık ve \% $65 \pm 5$ bağıl nem koşullarında iklimlendirme kabininde klimatize edilmiştir. Zımparalama işlemi için Grand (Asia Abrasive Industry) marka 60, 80, 100 ve 150 numaralı zımparalar kullanılmıştır. Zımparalama işlemi dekor zımpara mala oynar başlıklı el zımpara makinası kullanılarak yapılmıştır. Zımparalanan numunelerin yüzey pürüzlülük değerleri “MarSurf M 300” markalı yüzey pürüzlülüğü ölçüm cihazı kullanılarak ISO 4287 standardına göre ölçülmüştür. Yüzey pürüzlülüğü, $5 \mu \mathrm{m}$ çaplı elmas uçlu tarama iğnesi ile aşağ1-yukarı hareket etmek suretiyle numune yüzeyinde bulunan girinti ve çıkıntı profillerinin çıkarılması yöntemi ile ölçülmektedir. Test numunelerinin, profil çıkıntı ve girintileri arasında kalan merkez çizgisi ortalama pürüzlülük değerleri Ra, on nokta pürüzlülüğü $\mathrm{Rz}$ ve en büyük pürüzlülük değeri (Rmax) değerleri ölçülmüştür. Ölçümler için ölçme hızı $0,5 \mathrm{~mm} / \mathrm{sn}$, tarama uzunluğu $12,5 \mathrm{~mm}$, oda sıcaklığında ve sınır dalga boyu $\lambda \mathrm{c}=2,5 \mathrm{~mm}$ olarak belirlenmiştir. Her bir parametredeki bir numune için 4 ölçüm yapılmış ve 10 tekrarlı olmak üzere toplam 40 ölçüm yapılmıştır. Test numunelerine ait deney parametreleri Tablo1'de verilmiştir.

Tablo 1. Test Numunelerine Uygulanan Zımpara Numarası ve Kesiş Yönü

\begin{tabular}{ccc}
\hline \multirow{2}{*}{ Örnek No } & \multicolumn{2}{c}{ Kesiş Yönü ve Zımpara No } \\
\cline { 2 - 3 } & Teğet & Radyal \\
\hline Kontrol & 0 & 0 \\
Z-60 & 60 & 60 \\
Z-80 & 80 & 80 \\
Z-100 & 100 & 100 \\
Z-150 & 150 & 150 \\
\hline
\end{tabular}

\section{BULGULAR VE TARTIŞMA}

Çalışmada elde edilen Ra, Rz ve Rmax ortalama yüzey pürüzlülüğü değerleri ve standart sapma değerleri Tablo 2' de verilmiştir.

Tablo 2. Ra, Rz ve Rmax Ortalama Yüzey Pürüzlülüğü Değerleri ve Standart Sapma Sonuçları

\begin{tabular}{ccccccc}
\hline \multirow{2}{*}{ Göknar } & \multicolumn{3}{c}{ Teğet } & \multicolumn{3}{c}{ Radyal } \\
\cline { 2 - 7 } & $\begin{array}{c}\mathrm{Ra} \\
(\mu \mathrm{m})\end{array}$ & $\begin{array}{c}\mathrm{Rz} \\
(\mu \mathrm{m})\end{array}$ & $\begin{array}{c}\mathrm{Rmax} \\
(\mu \mathrm{m})\end{array}$ & $\begin{array}{c}\mathrm{Ra} \\
(\mu \mathrm{m})\end{array}$ & $\begin{array}{c}\mathrm{Rz} \\
(\mu \mathrm{m})\end{array}$ & $\begin{array}{c}\mathrm{Rmax} \\
(\mu \mathrm{m})\end{array}$ \\
\hline Kontrol & 7.45 & 44.09 & 58.70 & 7.83 & 42.92 & 72.23 \\
& $(0.34)^{*}$ & $(0.99)$ & $(0.54)$ & $(0.20)$ & $(4.09)$ & $(0.50)$ \\
Z-60 & 3.91 & 21.69 & 39.29 & 3.52 & 19.07 & 35.41 \\
& $(0.11)$ & $(0.71)$ & $(0.49)$ & $(0.28)$ & $(0.35)$ & $(0.49)$ \\
Z-80 & 3.56 & 20.98 & 28.52 & 3.48 & 19.00 & 24.76 \\
& $(0.15)$ & $(0.47)$ & $(0.45)$ & $(0.20)$ & $(0.57)$ & $(0.22)$ \\
Z-100 & 2.34 & 14.46 & 24.93 & 2.70 & 12.64 & 23.98 \\
& $(0.19)$ & $(0.88)$ & $(0.42)$ & $(0.19)$ & $(0.40)$ & $(0.47)$ \\
Z-150 & 1.54 & 10.86 & 16.50 & 1.74 & 11.35 & 21.04 \\
& $(0.11)$ & $(0.26)$ & $(0.70)$ & $(0.13)$ & $(0.97)$ & $(0.56)$ \\
\hline
\end{tabular}

*Parantez içindeki değerler standart sapma değerlerini göstermektedir.

Teğet yön için kontrol numunesinin ortalama Ra değeri $7.45 \mu \mathrm{m}, \mathrm{Rz} 44.09 \mu \mathrm{m}$ ve Rmax ise $58.7 \mu \mathrm{m}$ iken, Z-60 test grubu Ra değeri $3.91 \mu \mathrm{m}, \mathrm{Rz} 21.69 \mu \mathrm{m}$ ve Rmax ise $39.29 \mu \mathrm{m}, \mathrm{Z}-80$ test grubu Ra değeri $3.56 \mu \mathrm{m}, \mathrm{Rz} 20.98 \mu \mathrm{m}$ ve Rmax $28,52 \mu \mathrm{m}$, Z-100 test grubu Ra değeri $2.34 \mu \mathrm{m}, \mathrm{Rz} 14.16 \mu \mathrm{m}$ ve Rmax $24.93 \mu \mathrm{m}$ ve Z-150 test grubu Ra değeri $1.54 \mu \mathrm{m}, \mathrm{Rz} 10.86 \mu \mathrm{m}$ ve Rmax ise 16.5 olarak tespit edilmiştir (Şekil 1). 


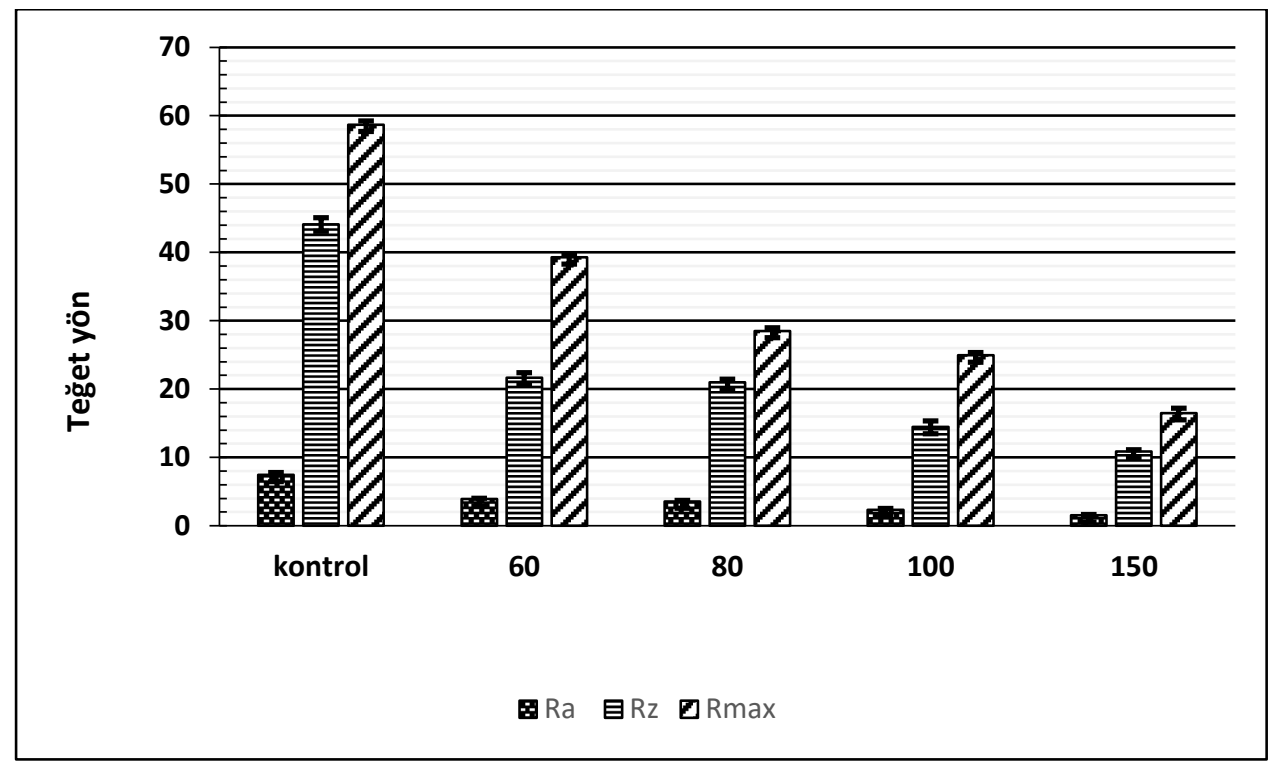

Şekil 1.Teğet Yön Ra, Rz ve Rmax Değerleri

Radyal yön kontrol numuneleri için ortalama Ra değeri $7.83 \mu \mathrm{m}$, Rz $42.92 \mu \mathrm{m}$ ve Rmax $7.23 \mu \mathrm{m}$ olarak tespit edilirken, Z-60 test grubu için Ra $3.52 \mu \mathrm{m}, \mathrm{Rz} 19.07 \mu \mathrm{m}$ ve Rmax $35.41 \mu \mathrm{m}, \mathrm{Z}-80$ test grubu için Ra $3.48 \mu \mathrm{m}, \mathrm{Rz} 19.00 \mu \mathrm{m}$ ve Rmax $24.76 \mu \mathrm{m}, \mathrm{Z}-100$ test grubu için Ra $2.7 \mu \mathrm{m}, \mathrm{Rz} 12.64 \mu \mathrm{m}$ ve Rmax $23.98 \mu \mathrm{m}$ ve Z-150 test grubu için Ra $1.74 \mu \mathrm{m}, \mathrm{Rz} 11.35$ $\mu \mathrm{m}$ ve Rmax 21.04 olarak belirlenmiştir (Şekil 2).

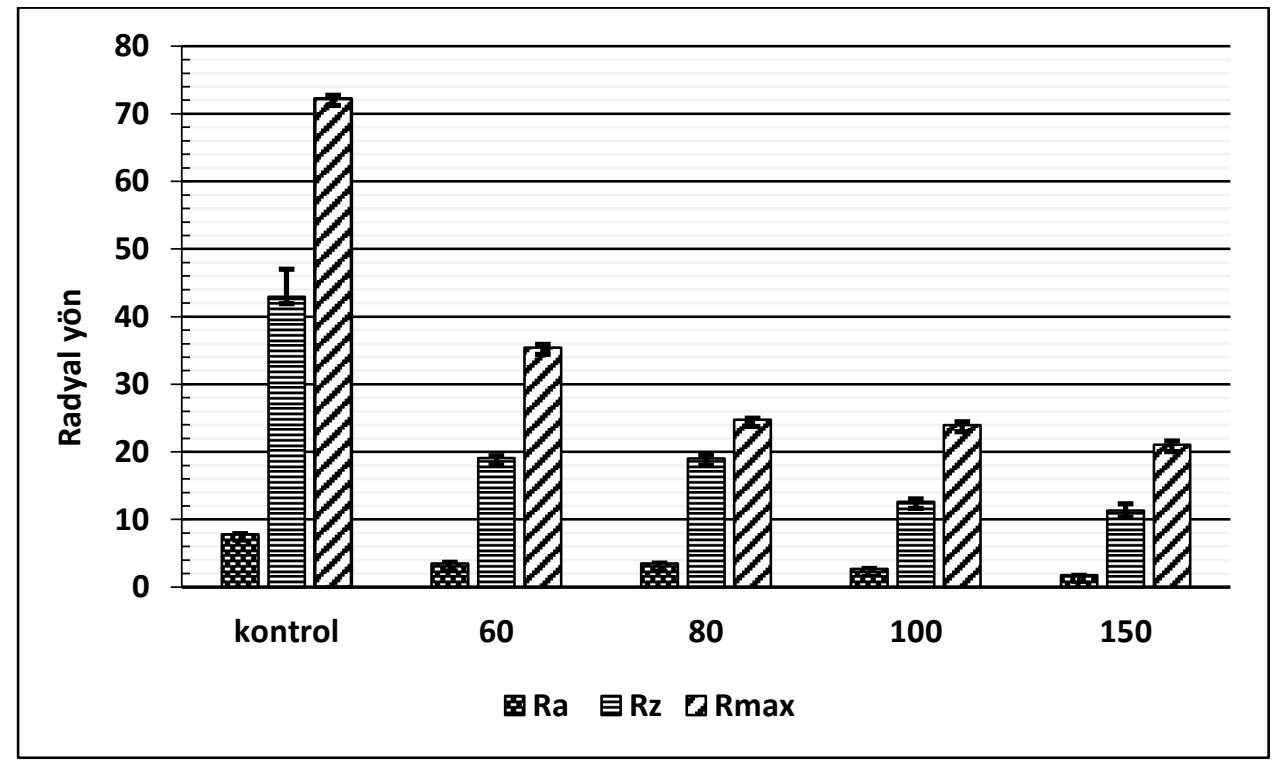

Şekil 2. Radyal Yön Ra, Rz ve Rmax Değerleri

Radyal yön için kontrol numunelerine kıyasla yüzey düzgünlüğünde meydana gelen iyileşme yüzde (\%) pürüzlülük oranları, Z-60 test numuneleri için $\mathrm{Ra} \% 55.0 \mu \mathrm{m}, \mathrm{Rz} \% 55.5 \mu \mathrm{m}$ ve Rmax ise $\% 50.9 \mu \mathrm{m}$ olarak elde edilmiştir. Z-80 test numuneleri ortalama Ra değeri $\% 55.5 \mu \mathrm{m}, \mathrm{Rz} \% 55.7 \mu \mathrm{m}$ ve Rmax $\% 65.7 \mu \mathrm{m}, \mathrm{Z}-100$ test numunelerinde $\mathrm{Ra} \% 65.5 \mu \mathrm{m}, \mathrm{Rz}$ $\% 70,5 \mu \mathrm{m}$ ve Rmax $\% 66.8 \mu \mathrm{m}$ ve Z-150 test numunelerinde $\mathrm{Ra} \% 77.7 \mu \mathrm{m}, \mathrm{Rz} \% 73.5 \mu \mathrm{m}$ ve Rmax \%70.9 olarak tespit edilmiştir. Tablo 3' de Ra, Rz ve Rmax için yüzey düzgünlüğünde belirlenen iyileşme yüzde (\%) oranları verilmiştir. 
Tablo 3. Test Numunelerinin Yüzey Pürüzlülük Parametrelerindeki İyileşme Oranları (\%)

\begin{tabular}{ccccccc}
\hline \multirow{2}{*}{$\begin{array}{c}\text { Göknar Ahşabı Test } \\
\text { Numuneleri }\end{array}$} & \multicolumn{3}{c}{ Teğet (\%) } & \multicolumn{3}{c}{ Radyal (\%) } \\
\cline { 2 - 7 } & $\mathrm{Ra}(\mu \mathrm{m})$ & $\mathrm{Rz}(\mu \mathrm{m})$ & $\mathrm{Rmax}(\mu \mathrm{m})$ & $\mathrm{Ra}(\mu \mathrm{m})$ & $\mathrm{Rz}(\mu \mathrm{m})$ & $\mathrm{Rmax}(\mu \mathrm{m})$ \\
\hline Z-60 & 47.5 & 50.8 & 33.1 & 55.0 & 55.5 & 50.9 \\
Z-80 & 52.2 & 52.4 & 51.4 & 55.5 & 55.7 & 65.7 \\
Z-100 & 68.6 & 67.2 & 57.5 & 65.5 & 70.5 & 66.8 \\
Z-150 & 79.3 & 75.3 & 71.8 & 77.7 & 73.5 & 70.9 \\
\hline
\end{tabular}

Teğet yön için kontrol numunemize kıyasla yüzde(\%) pürüzlülük değerlerinin, Z-60 test grubu için Ra değeri \%47.5 $\mu$ m, $\mathrm{Rz} \% 50.8 \mu \mathrm{m}$ ve Rmax \%33.1 $\mu \mathrm{m}$ oranlarında iyileşme gösterdiği belirlenmiştir. Bu iyileşmenin yüzey parametre değerlerinde Z-80 test grubu için Ra \%52.2 $\mu \mathrm{m}, \mathrm{Rz} \% 52.4 \mu \mathrm{m}$ ve Rmax \%51.4 $\mu \mathrm{m}, \mathrm{Z}-100$ test grubu için Ra \%68.6 $\mu \mathrm{m}, \mathrm{Rz} \% 67.2 \mu \mathrm{m}$ ve Rmax \%57.5 $\mu \mathrm{m}$ ve Z-150 test grubu için Ra \%79.3 $\mu \mathrm{m}, \mathrm{Rz} \% 75.3 \mu \mathrm{m}$ ve Rmax \% 71.8 olduğu tespit edilmiştir.

$\mathrm{Bu}$ çalışmada elde edilen verilere göre zımpara numarası arttıkça yüzey pürüzlülüğü azalmıştır. Daha önce yapılan çalışmada da benzer sonuçlar bulunmuştur (İstek ve ark., 2012). Radyal yöndeki ölçümlerin teğet yöne göre daha pürüzlü yüzeyler vermesi ahşap yüzey yapısının ve yüzey yapı büyüklüklerinin farklı olmasından kaynaklanmış olabilir.

Söğütlü (2005) tarafından yapılan çalışmalar ile karşılaştırıldığında sonuçların literatür ile uyumlu olduğu tespit edilmiştir. Zımpara numarasının artması birim alanda bulunan tane sayısının ve aşındırıcı kum tane hacminin küçülmesi anlamına gelmektedir. İri hacimli aşındırıcılar yani küçük numaraya sahip zımparalar yüzeyde çizikler meydan getirerek aşındırma yapmaktadır. Büyük numaralı zımparalar küçük tanelerden (kum) oluşmaktadır. Küçük taneli büyük numaralı zımparalar ile işlenen malzeme yüzeylerinde aşınma miktarı azalmakta ve çok derin yüzey bozuklukları oluşmamaktadır. Sönmez ve ark. (2002) ile Efe ve ark. (2002), tarafından yapılan çalışmalarda küçük kum taneli (büyük numaralı) zımparaların, büyük taneli (küçük numaralı) zımparalara göre, yüzey pürüzlülüğü açısından avantaj sağlaması literatürle uyumludur (Efe ve ark., 2007). Göknar ahşabı kontrol ve kesiş yönüne (teğet ve radyal) test örneklerinin yüzey pürüzlülük profilleri Şekil 3a, 3b, 3c ve 3d'de gösterilmiştir.

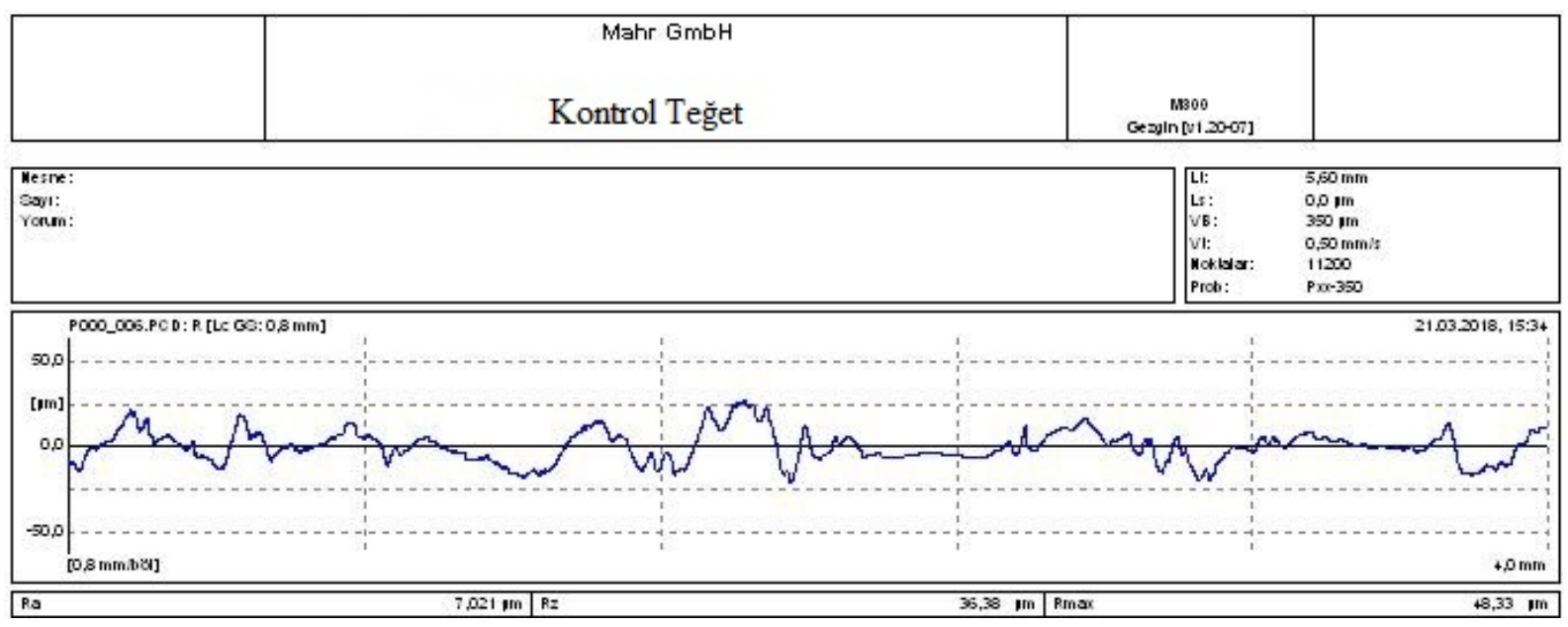

Şekil 3a. Göknar Ahşabının, Teğet Yön Kontrol Test Örneklerine Ait Yüzey Pürüzlülük Profili 


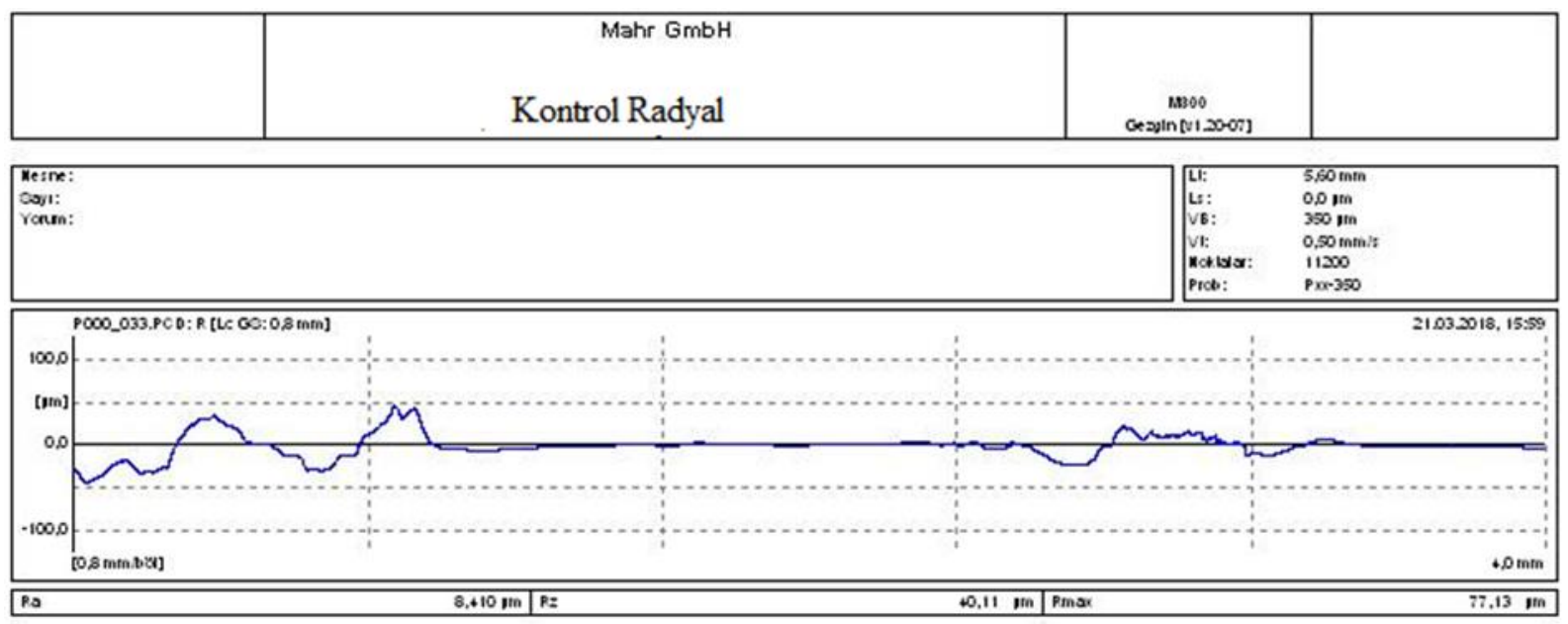

Şekil 3b. Göknar Ahşabının, Radyal Yön Kontrol Test Örneklerine Ait Yüzey Pürüzlülük Profili

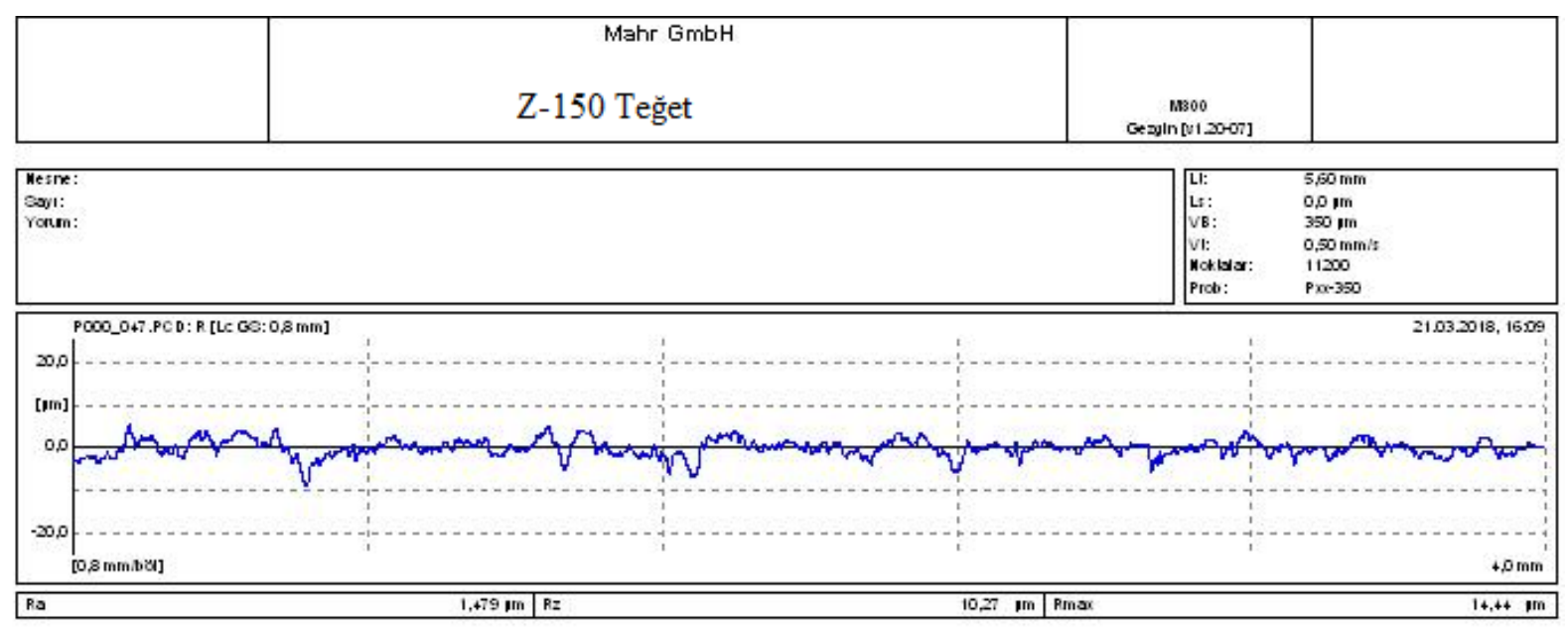

Şekil 3c. Göknar Ahşabının, Teğet Yön Z-150 Test Örneklerine Ait Yüzey Pürüzlülük Profili

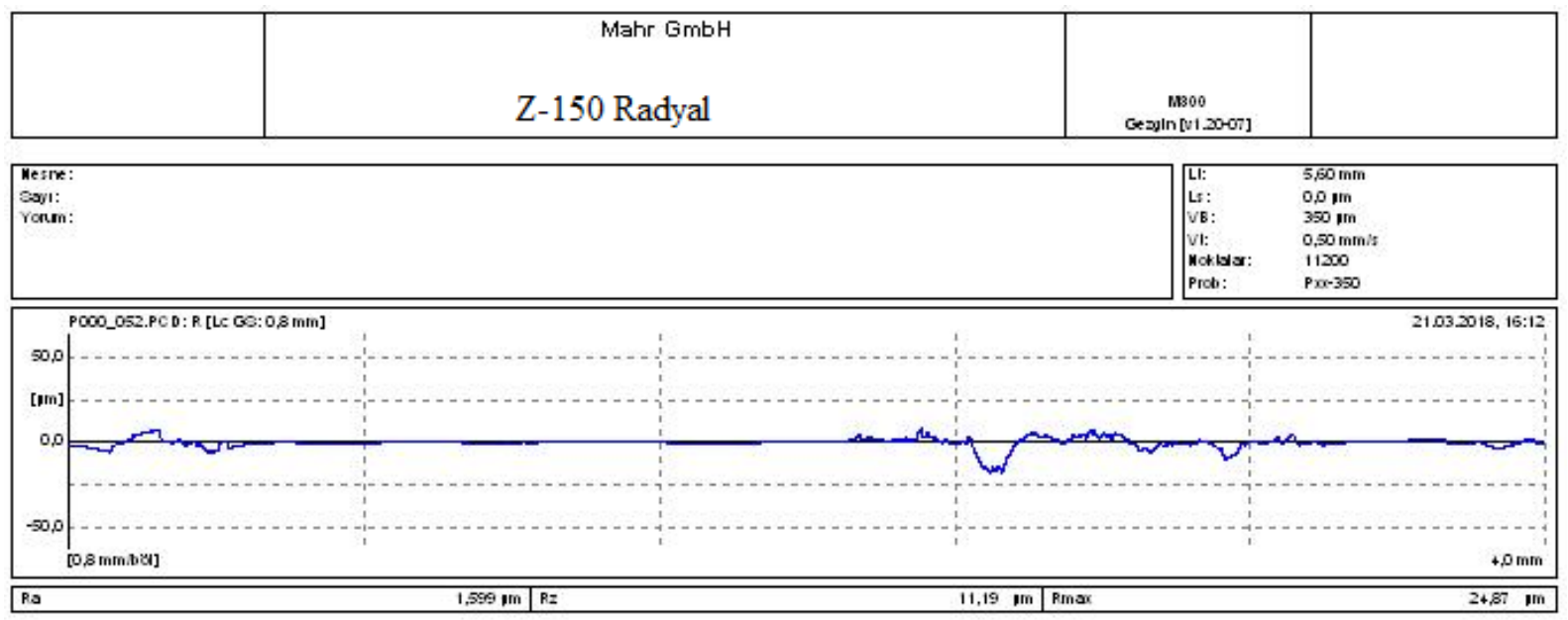

Şekil 3d. Göknar Ahşabının, Radyal Yön Z-150 Test Örneklerine Ait Yüzey Pürüzlülük Profili 


\section{SONUÇ VE ÖNERILER}

Elde edilen verilere göre;

1. Teğet ve radyal yöndeki numuneler kontrol numunesi ile kıyaslandığında teğet yönde zımparalama işlemi uygulanan numunelerin radyal yöndeki numunelere göre yüzey pürüzlülük değerlerini daha olumlu etkilediği belirlenmiştir.

2. Zımpara numarası arttıkça yüzey pürüzlülüğünde iyileşmeler tespit edilmiştir.

3. Teğet ve radyal yönde en iyi yüzey pürüzlülüğü değerleri Z-150 test grubunda elde edilmiştir. Teğet yön için $1.54 \mu \mathrm{m}$ ve radyal yön için $1.74 \mu \mathrm{m}$ olarak elde edilmiştir.

4. Kontrol numunesine kıyasla yüzey pürüzlülük parametre değerlerinde iyileşme yüzde (\%) oranları Ra, Rz ve Rmax için teğet yönde sırasıyla $\% 79.3, \% 75.3$ ve $\% 71.8 \mu$ m olarak elde edilmiştir.

5. Bu sonuçlar ışı̆̆ında mobilya sektöründe büyük numaralı zımpara kullanılması malzemelerin yüzey düzgünlük kalitesini arttıracaktır. Özellikle dekoratif malzeme üretiminde pürüzsüz yüzeylerin elde edilebilmesi için mutlaka büyük numaralı zımpara kullanılmalıdır.

\section{KAYNAKLAR}

Ayrılmış, N., Candan, Z., Akbulut, T., Balkiz, O., (2010). Effect of sanding on surface properties of medium density fiberboard, Drvna industrija: Znanstveni časopis za pitanja drvne tehnologije, 61(3), 175-181.

Efe, H., Gürleyen, L., (2007). Farklı zımparalarla zımparalanmış ve poliüretan tutkalı ile yapıştırılmış bazı ağaç malzemelerin yapışma dirençleri, Politeknik Dergisi, 10(2), 185-189.

Efe, H., Gürleyen, L., Kasal, A., (2002). Dört kesicili jilet bıçak topu ile işlenmiş masif ağaç malzemede devir sayısının yapışma performansına etkileri, Gazi Üniversitesi Fen Bilimleri Enstitüsü Dergisi, C, 15, 429-438.

Funck, J. W.,Forrer, J. B., Butler, D. A., Brunner, C. C., Maristany, A. G., (1993). Measuring surface roughness on wood: a comparison of laser-scatterand stylus-tracing approaches, In Proc. Industrial applications of optical inspection, metrology, and sensing (Vol. 1821, 173-185). International Society for Optics and Photonics.

Hızıroğlu, S., (1996). Surface roughness analysis of wood composites: a stylus method, Forest Products Journal, 46(7, 8), 67.

ISO 4287 (1997). Geometrical Product Specifications Surface Texture Profile Method Terms. Definitions and Surface Texture Parameters (Standard No: ISO 4287), International Organization for Standardization, Geneva, Switzerland.

İstek, A., Kara, M.E., Karakaya, B., (2012). Lif levhaların yüzey pürüzlülüğü üzerine bazı zımparalama faktörlerinin etkisi, Bartın Orman Fakültesi Dergisi, 14(22), 41-46.

Kılıç, M., Burdurlu, E., Aslan, S., Altun, S., Tümerdem, Ö., (2009). The effect of surface roughness on tensile strength of the medium density fiberboard (MDF) over laid with polyvinylchloride (PVC), Materials \& Design, 30(10), 4580-458.

Örs, Y., Baykan, İ., (1999). The effect of planning and sanding on surface roughness of massive wood, Turkish Journal of Agriculture and Forestry, 23, 577-582.

Örs, Y.,\& Demirci, S., (2003). Akasya ve Meşe ahşaplarında yüzey düzgünlüğüne kesiş yönü ve zımparalamanın etkisi, $G \ddot{U}$ Teknik Ĕgitim Fakültesi Politeknik Dergisi, 6(2), 491-495.

Peters, C. C., Cumming, J. D., (1970). Measuring wood surfaces moothness: a review, Forest Products Journal, 20(12), 40-3.

Schoenfeld, B. J., Contreras, B., Willardson, J. M., Fontana, F., Tiryaki-Sonmez, G., (2014). Muscle activation during lowversushigh-load resistan cetraining in well-trained men. European journal of applied physiology, 114(12), 2491-2497.

Söğütlü, C., (2005). Bazı faktörlerin zımparalanmış ağaç malzeme yüzey pürüzlülüğüne etkisi, Politeknik dergisi, 8(4), 345350 .

Sönmez, A., Budakçı, M., Gürleyen, L., (2002). Yaprak bıçaklarla (hss) işlenmiş akasya ahşabında yüzey düzgünlüğünün yapışma direncine etkisi, Gazi Üniversitesi Endüstriyel Sanatlar Ĕ̈itim Fakültesi Dergisi, Y, 9, 9.

Stumbo, D. A., (1963). Surface texture measurement method, Forest Prod J, 7, 299-304.

Yaltırı, F., Efe, A., (2000). Dendroloji, İstanbul Üniversitesi Orman Fakültesi Yayınları, No:465, Ders Kitabı, İstanbul, 66$68 \mathrm{~s}$. 